\title{
Algoman: Gearing up for the "Net Generation" and Era of Artificial Intelligence, One Step at a Time
}

\author{
Satish Deopujari ${ }^{1}$ (D) $\cdot$ Ayush Shrivastava ${ }^{2} \cdot$ Akruti Gore Joshi $^{3} \cdot$ Ashwin Meshram $^{4} \cdot$ Shashikant Chaudhary $^{5}$
}

Received: 21 August 2019 / Accepted: 23 August 2019/Published online: 16 October 2019

(C) The Author(s) 2019

Apps in medicine are based on algorithms and are getting increasingly used, specially in critical care $[1,2]$. Some of these apps are time sensitive and thus have given rise to the concept of "golden minute" and have helped reduce mortality. Unfortunately, these algorithms are still not very easily available at bedside, specially on devices like mobile phones. In contrast to its competitors e.g., Algomed, Algoman allows the user to create algorithms.

There is no denying that there is a e-revolution in medical education and practice [3]. The era of artificial intelligence in medicine is approaching fast [4]. ALGOMAN is a timely intervention to gear up the "net generation" of medical students, medical educators and clinicians.

Algoman creates algorithms that turn into an app on the smartphones that can act like "pocket brains". This waives off the need to navigate through the increasing volumes of medical literature before making life critical decisions in time limited settings of the intensive care unit (ICU) [2].

The process of creating algorithm is as follows: After you login to the website, go to create algorithms. Click

Satish Deopujari

deopujaris@gmail.com

1 Department of Pediatrics, Nelson Mother \& Child Care Hospital, Dhantoli, Nagpur, Maharashtra, India

2 Department of Pediatrics, Jawaharlal Nehru Medical College, Datta Meghe Institute of Medical Sciences (Deemed to be University), Sawangi, Meghe, Wardha, Maharashtra, India

3 Nucleus Children Hospital, Dhantoli, Nagpur, Maharashtra, India

4 Spinnaker LLC, Mumbai, India

5 Cofounder Nagpur Angels, Ex-managing Director Global Logic, Nagpur, India on the boxes, key in the text. The four dots on each of the box turn green when clicked, connect one dot to the other dot on another box by clicking on the latter. If you add step/ block, additional boxes get added, thus creating an algorithm (Fig. 1).

Algorithms have one major problem and that is they are vulnerable to changes and these are a corollary to ongoing research, for every change one needs to go through the process of coding and this means cost and time spent on going through the whole process repeatedly. Algoman is a simple solution to the complex problem of changing algorithms, and makes it easy to make an app on smartphones.

Computerized health diagnostics and decision making algorithms can provide timely clinical decision support at bedside and improvise the process of adherence to evidence based guidelines, and be a source for education and research [2]. Moreover, these algorithms can be integrated with hardware, and embedded with machine learning modules, to develop a fully functional artificial intelligence-based medico bot.

Thus, to conclude, Algoman can imbibe algorithmic learning which will be the future of medicine. Algorithms would 
P.C. Create algorithm www.algoman.in

$\uparrow$

Edit and keep learning

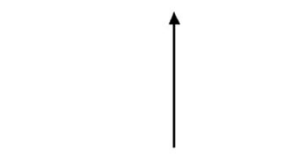

Algoman app on apple store / play store
Save and edit

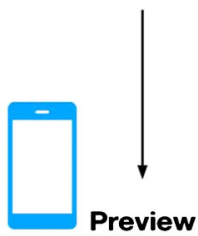

How it will be seen on mobile

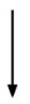

Share it on a selected group or make it public

Fig. 1 The working of an Algoman

create precision in diagnosis and management [4]. The future would be to add checklist to Algoman.

Open Access This article is distributed under the terms of the Creative Commons Attribution 4.0 International License (http:// creativecommons.org/licenses/by/4.0/), which permits unrestricted use,

distribution, and reproduction in any medium, provided you give appropriate credit to the original author(s) and the source, provide a link to the Creative Commons license, and indicate if changes were made.

\section{References}

1. Rajkomar A, Dean J, Kohane I. Machine learning in medicine. New Engl J Med. 2019;380:1347-58.

2. Schwarz D, Štourač P, Komenda M, et al. Interactive algorithms for teaching and learning acute medicine in the network of medical faculties MEFANET. J Med Internet Res. 2013;15:e135.

3. Dhir SK, Verma D, Batta M, Mishra D. E-learning in medical education in India. Indian Pediatr. 2017;54:871-7.

4. Jiang F, Jiang Y, Zhi H, et al. Artificial intelligence in healthcare: past, present and future. Stroke Vasc Neurol. 2017;2:230-43.

Publisher's Note Springer Nature remains neutral with regard to jurisdictional claims in published maps and institutional affiliations. 